Vol. 38(2), pp. 245-259, Dec. 2019

ISSN 1821-536X (print)

ISSN 2619-8789 (electronic)
Tanzania Journal of Engineering and Technology

Copyright (C 2019 College of Engineering and Technology, University of Dar es Salaam

Review Paper

\title{
Reviewing the Potential and Constraints of Modified Technology Options for Faecal Sludge Management in Dar es Salaam, Tanzania
}

\author{
Amour Seleman $^{1 *}$, Tolly S.A. Mbwette ${ }^{1}$, Sara Gabrielsson²and Richard Kimwaga1 \\ ${ }^{1}$ Department of Water Resources Engineering, College of Engineering and Technology, \\ University of Dar es Salaam, P. O. Box 35131, Tanzania \\ ${ }^{2}$ Lund University Centre for Sustainability Studies (LUCSUS), Lund University, \\ Sweden \\ *Corresponding author: matipula@ hotmail.com
}

\begin{abstract}
Cities in the developing world face the challenge of safe management of faecal sludge because of rapid population growth that overwhelms the sanitation infrastructure and services. In developing countries, only 50\% of faecal sludge (FS) generated is safely managed the remaining portion is haphazardly disposed of in the environment risking public health and environment. In response to the urgent need for safely managed sanitation services, technological options for containment, desludging and transportation of FS are being modified. This paper reviewed current desludging practices and the potential of modified technological options for addressing FSM at containment, desludging, and transportation in Dar es Salaam unplanned urban settlements. The paper reviewed; water seal squat pan, Urine Diversion Dry Toilet $(U D D T)$, split slabs, pre-installed suction hose, and the container-based sanitation (CBS) for containment stage. Others are the hand tools, sludge digger, the excrevator, rammer, and the eVac for desludging; and small pick-up truck and motorized tricycle and transfer stations for transfer and transportation of FS. Based on technical feasibility, social and environmental context of Dar es Salaam, the reviewed modified technology options have the potential of addressing FSM challenges in unplanned urban settlements in Dar es Salaam. However, institutional arrangement particularly the absence of the modified technologies in the menu of recommended technological options affects their upscaling. Paradoxically, most of the technologies have not been vigorously tried in the field to inform policy choice. Improvement of FSM with the application of modified technological options will require improvement in enabling environment for their operation and continuous modification. The major research gaps have also been identified in this review.
\end{abstract}

Keywords: Containment, Desludging, Faecal Sludge Management, Modified technology options Non-sewered sanitation.

\section{INTRODUCTION}

The importance of effective containment, desludging and transportation of faecal sludge (FS) to health and environmental is widely documented in the literature (WHO, 2018; Strande et al., 2014; Hawkins et al., 2013). The three 
components combined achieve collection of excreta, storage, safe removal and transportation of FS from non-sewered sanitation facilities to treatment facilities for further treatment and safe disposal or reuse hence maintaining a sanitary environment (Tilley et al., 2014). However, in most unplanned urban settlements (UUS) in low and medium income countries (LMIC) containment, desludging and transportation is usually ineffective leading to exposure of FS to the surrounding environment and consequently posing risk to human health and environment (UNICEF and WHO, 2019).

Research on the magnitude and prevalence of ineffective containment, desludging practices and transportation is scant, and
LMIC have had little success in estimating the proportion of their population with access to effective faecal sludge management (FSM) services (UNICEF and WHO, 2019). However, it is estimated that on average, cities in LMIC effectively manage only $50 \%$ of the total amount of FS generated (Strande et al., 2014). The remaining amount is left in pits for a long period or haphazardly disposed of in the surrounding environments. Review of Shit Flow Diagrams (SFD) of various cities show that these three segments contributes to the large proportion of FS that escapes from FSM chain (SuSanA, 2019). For example, in Dar es Salaam, the components contribute $48 \%$ of faecal sludge (FS) that escapes from the management chain (Figure 1).

\section{Dar es Salaam, Tanzania, 03.09.2015}

Field based assessment

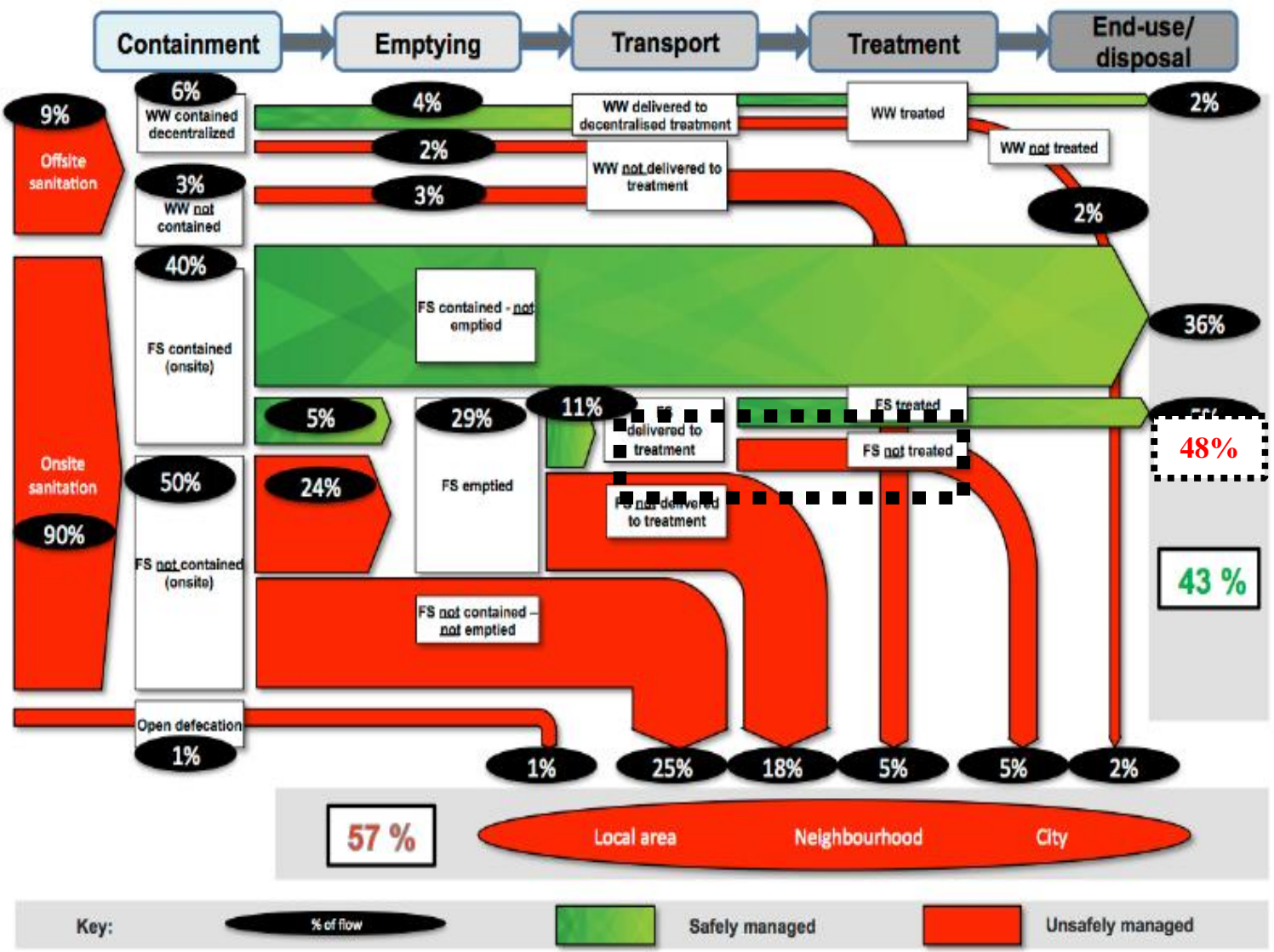

Figure 1: Flow of faecal sludge in Dar es Salaam Source (Brandes et al., 2015). 
The prevalence of poor FSM in UUSs has been known to be caused in part by the use of technological options that are ineffective (GOAL, 2016; EOOS and WEDC, 2014). UUSs are characterized by narrow lanes and long distance to FS discharge points hence affects economic transportation. Dense faecal sludge, high solid waste content in pits, very deep pits and lack of access hole to pits limits desludging technologies (Semiyaga et al., 2015; Strande et al., 2014; Katukiza et al., 2012). In response to the challenges and the need to attain the Sustainable Development Goals (SDGs) of attaining universal access to safely managed sanitation by 2030, modifications are made on sanitation technological options. However, it is unclear whether the modified technological options have the potential of addressing current and future FSM challenges.

It was further established that sanitation options ought to be sustainable such that it promotes human health, protect the environment and natural resources are technically and institutionally appropriate, economically viable and socio-culturally acceptable through its design and how it renders services (SuSaNa, 2008). This paper provides a potential review of the modified technological options for containing, desludging, and transportation of faecal sludge within the framework of sustainable sanitation. The paper examines the design of the technologies, the challenges that they aim to address, then evaluated their potential and constraints in the application in Dar es Salaam based on their advantages and disadvantages. Only those technology options that seem to be viable in low income country's context such as being simple, low cost and easy to maintain were considered over high -tech designs (Mara et al., 2007).

\section{Modified Technology Options at the Containment Stage}

\section{Water-seal pan}

The water-seal pans are water-based pan with a "U" shaped water seal. Apart from limiting foul smell from the pit and limiting movement of insects towards and from the pit, it also limits the entry of solid wastes (Mara, 1985). The restriction of solid wastes makes the design useful option for the control of entry of solid wastes into the pit thus resulting in faecal sludge that can easily be desludged (Duncan, 1985). The solution has the potential of addressing FSM challenges in Dar es Salaam because solid waste content is widely reported. It is estimated that, one toilet pit may contain up to 50 buckets of ten litres volume (Brandes et al., 2015) and has frequently interfered desludging by a manual pump and vacuum tankers.

The potential application of water-seal pan as an option for the control of solid waste into pits in Dar es Salaam is high because of technical, institutional and social factors. In Dar es Salaam, $70 \%$ of the toilets are lined (Jenkins et al., 2014) and only a few (38\%) residential houses have installed water seal pans in toilets (URT, 2015) as such number of potential users is high. Water seal pan has been included in the National Sanitation Guidelines (URT, 2016), hence institutionally acceptable. Furthermore, the use of this water based design is likely to receive acceptance by users because over $90 \%$ of residents use water as anal cleansing material (Chaggu, 2004). However, the anticipated challenges on a wide use of water seal squat pan is on the need for alternative acceptable mechanism for collection of used sanitary pads that are currently thrown into pits because of cultural reasons (Brandes et al., 2015) and also the inadequate water supply. 
The effective operation of water seal squat pan is achieved when the water supply is piped into a dwelling or plot (Mara, 1985). In Dar es Salaam, only $20.1 \%$ and $12.9 \%$ have water supply piped into the dwellings and yard, respectively (NBS, 2015). The majority are served by public water kiosks, although currently, in other parts of Tanzania such as Njombe District, the use of water seal pan has been common even when water is obtained at communal collection points (Safari et al., 2019). The challenge of disposal mechanism for sanitary pads can be addressed through health education (Strande et al., 2014) and therefore technical, institutional and social reasons favours applicability of the water seal squat pan in Dar es Salaam for improvement of FSM.

\section{Urine Diversion Dry Toilets}

Dry toilets such as Urine Diversion Dry Toilets (UDDT) were developed with a primary purpose of resource recovery (Chaggu, 2004). Nevertheless, their benefits go beyond resource recovery to address the challenge of high-water content and pathogens load in faecal sludge. The UDDT toilets have two compartments that are used in alternation for storage of faecal sludge hence eliminate the need for extra space for the construction of new pit once it is full. The facility is constructed on the ground hence eliminate the need for excavation of pit, thus suitable in rocky and places with high water table levels. Furthermore, the UDDT toilet maintains dry and alkaline conditions, high temperature and exposes sludge to solar radiations hence reduces pathogens load compared to normal latrines (Chaggu, 2004).

In Dar es Salaam, about $60 \%$ of residential plots in unplanned urban settlements are located in areas with high water table and high infiltration rates (Jenkins et al., 2015). There is thus a potential application of
UDDT in these areas. The UDDT have received acceptance institutionally as they have been included in the menu of improved toilets to be adopted (URT, 2016). Furthermore, desludging dry FS is likely to improve the health of manual pit emptier who currently use simple tools and yet enter the pit for desludging, the action that endangers their health and safety. Death of pit emptiers due to the collapse of pits have been reported in Dar es Salaam (WaterAid, 2010). However, the construction of UDDT requires qualified personnel who are usually lacking in most unplanned urban settlements (Jenkins et $a l .$, 2015). Furthermore, the UDDT latrine may face rejection socially due to the need to move aside during anal cleansing a challenge that have been widely associated with UDDT in other parts of Tanzania (Mayo and Mubarak, 2015) .

\section{Split slab}

Split slabs are designed to allow easy access to the pit contents without breaking open the slab for emptying when the pit is full (Plate 1). Structurally, the split slab can be round or rectangular (Morgan, 2013). When the pit is full, one piece is removed to allow emptying with manual tools. This technique is beneficial to residential houses that rely on dry toilets such as VIP latrines, and houses in congested areas inaccessible to vacuum tankers or with deep pits inaccessible to manual operated equipment such as the Gulper. With split slab, emptiers remove sludge from the pits without entering them, hence reduces the risk of falling and injury from harmful sharps and gases (Strande $e t$ al., 2014).

The use of split slabs in Dar es Salaam can have a high potential in serving lives and improve the health of manual emptier. Deaths of manual emptier "frogmen" are reported in Dar es Salaam (WaterAid, 2010). However, the solution may be 
technically not feasible in the current unplanned urban settlements because of the need to rehabilitate the entire toilet compartment, which may turn to be economically impractical (Thye et al., 2011). In unplanned urban settlements in Dar es Salaam, potential users comprise of those with unimproved toilets which are as few as 29.1\% (URT, 2015). Therefore, split slab can be used in areas where new construction is taking place. High growth rate of 5.6\% in Dar es Salaam goes parallel with the construction of new residential houses in the outskirts of the city to accommodate the increasing population. These may form new potential users of the split slabs to minimize emptying challenges in the future (URT, 2019a).

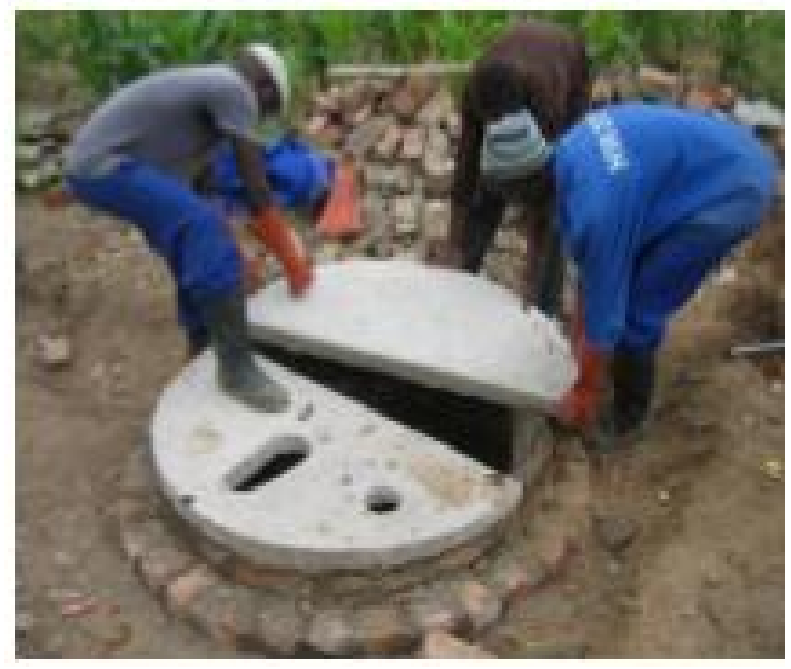

Plate 1: Split slab - two "half-moon" slabs (Morgan, 2013)

\section{Pre-installed suction hose}

The pre-installed suction hose provides a mechanism for fluidization and suction of faecal sludge from outside (Manus, 2011). The suction hose is introduced through the slab to the base where water can be pumped in and sludge sucked out (Figure 2 ). The pit adopted for the pre-installed suction hose is pre-fabricated and relatively shallow, around $1.5 \mathrm{~m}$ deep making it easy to desludge by several manual operated equipment such as Gulper and eVac and suitable for areas with high water table (Chipeta et al., 2017).

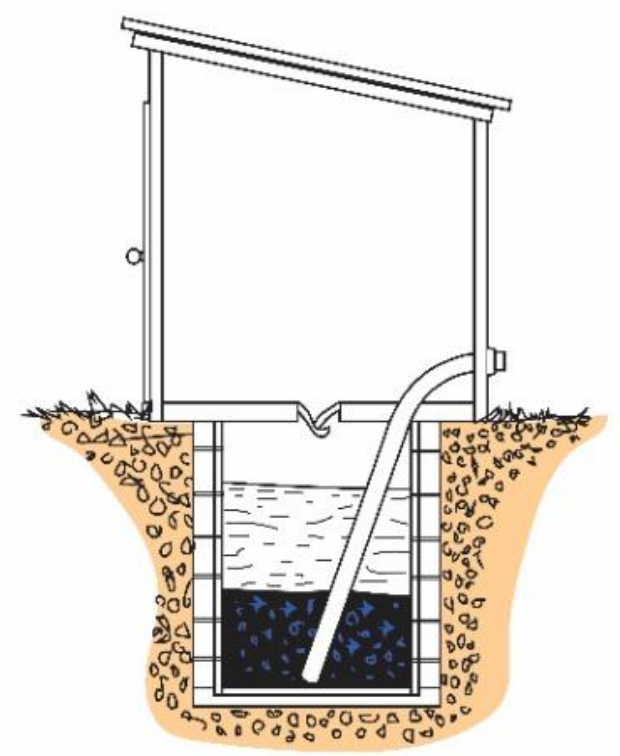

Figure 2: A cross sectional view of a pit latrine with a pre-installed suction hose (Manus, 2011).

The potential for application of preinstalled suction hose in Dar es Salaam lies on the reason that still manual emptying is practiced and therefore adoption of the technology will improve health and safety of manual pit emptiers when adopted. Statistics on the prevalence of injury and fatal accidents due to manual pit emptying in Dar es Salaam are scarce although incidences are frequently reported (Brandes et al., 2015). In 2010, seven deaths of manual pit emptiers were reported in Dar es Salaam and still, manual emptying remains a major alternative desludging method (WaterAid, 2010; Jenkins et al., 2015). Furthermore, the potential application of the technology is on the situation that some residential plots in Dar es salaam are located in areas with high water table hence the shallow pit used in pre-installed hose technology is likely to address challenges limiting pit excavation in these areas. 
Among the foreseen constraints on the application of the pre-installed hose pipe in Dar es Salaam is that about $30 \%$ of toilets in Dar es Salaam are unlined (Jenkins et al., 2014). Rehabilitation for installing suction hose may be expensive as the entire pit may need improvement. Furthermore, the operation of this new pit design will require reintroduction of other desludging equipment to replace the UN HABITAT Vacutug which exists currently in Dar es Salaam (Thye et al., 2011). The design may require institutional reforms since currently the design has not been included in the national sanitation guidelines (URT, 2016).

\section{Container based sanitation}

Container Based Sanitation (CBS) are sealable containers designed to receive and store excreta. The size of CBS varies; the portable mode has a container of about 20 litre container for capturing faeces and a $3.8 \mathrm{~L}$ container for a collection of urine (WBG, 2019; Tilmans et al., 2015; EOOS and WEDC, 2014). After every visit, the user covers excreta with special cover materials such as a mixture of sugarcane bagasse and crushed peanut shells to control smell and flies (Tilmans et al., 2015). Filled up faeces container is collected and transported to a central collection and treatment facility where the containers are cleaned for later re-use. The technology has several advantages in containment, desludging, and transportation of faecal sludge. It minimizes the possibility of getting into direct contact with faeces since desludging is replaced by a collection of the entire container.

The small size renders CBS technology suitable in densely populated areas with limited space for the construction. The portability feature makes the technology suitable in areas characterized by high water table, prone to flooding, hilly, rocky and collapsing soil (WBG, 2019; Tilmans et al., 2015). In these places, CBS achieve the inclusive sanitation and eliminates open defecation (Russel et al., 2019; Katukiza et al., 2012). The CBS has been mostly used during emergencies, unplanned urban settlement and in special requirements such as to serve people with impaired mobility such as people with disabilities, the sick or the elderly who cannot access the normal sanitation facilities.

In Dar es Salaam, CBS can benefit over $60 \%$ of residential plots in unplanned urban settlements are located in low land, with high water table and risk o flooding (Brandes et al., 2015). In these areas, CBS can be used particularly during flood events as an emergency sanitation solution than resorting to flying toilets or open defecation. CBS can also serve as an alternative solution to meet sanitation needs of people with special needs particularly houses that have adopted mound toilets which are inaccessible for people with disabilities, the elderly and sick. In Dar es Salaam mound toilets with raised superstructure are common in areas such as Majumbasita as an adaptation strategy for high water table (Chaggu, 2004). However, the introduction of CBS in Dar es Salaam may face institutional and cultural challenge. CBS has not been identified as one of the sanitation policy option (URT, 2016). Therefore, its acceptance may depend on policy and institutional arrangements that are set to favour running of CBS program. Most of CBS are urine diverting dry toilets (UDDT), a feature that may lead to low social acceptability among "washers" who are the majority in Dar es Salaam (Jenkins et al., 2015; Chaggu, 2004). 


\section{Modified Technology Options for Desludging}

\section{Modified hand tools for desludging}

The modified hand tools for manual pit emptying include long-handled shovels, hay rake and hooks (Plate 2). These tools are used along with safety gears particularly face masks, eye protection, gloves, boots, hardhat, overalls, disinfectants for cleaning up (WHO, 2018). The ability of hand tools to work effectively with dense faecal sludge and high solid waste content in high density areas has made hand tools to persist for decades (GOAL, 2016). The modified hand tools rely on local labour, low capital and operational cost and the process is less affected by breakdowns in machinery or running out of fuel (GOAL, 2016). The tools have the capability of emptying the entire pit, unlike other desludging methods that seldom do so (Thye et al., 2011). Nevertheless, the viability of these tools depend on reliable transport means to avoid haphazard disposal of faecal sludge in surroundings (Thye et al., 2011). These modified tools are difficult to use when they are heavy and very long to reach pits deeper than $4 \mathrm{~m}$ (O'Riordan, 2009).

The technical and social context of Dar es Salaam may favour the application of the modified manual hand tools. The use of dry pit latrines which cannot be desludged with vacuum tanker are still common in Dar es Salaam whereby over $60 \%$ of residents in use dry type toilets such as VIP latrines and other pit latrines (URT, 2015). Emptying using manual tools is socially acceptable as indicated by the prevalence of manual pit emptying in the city (Jenkins et al., 2015). The use of modified hand tools may face challenges especially when they are to be used along with personal protective equipments to enhance their safety. The compliance of manual pit emptiers on the use of personal protective equipments may be low because of high temperature and humidity in Dar es Salaam (Dar) that discourage their use (Keller et al., 2017). Dar es Salaam temperature range between $24-27^{\circ} \mathrm{C}$ (Brandes et al., 2015) which is high.

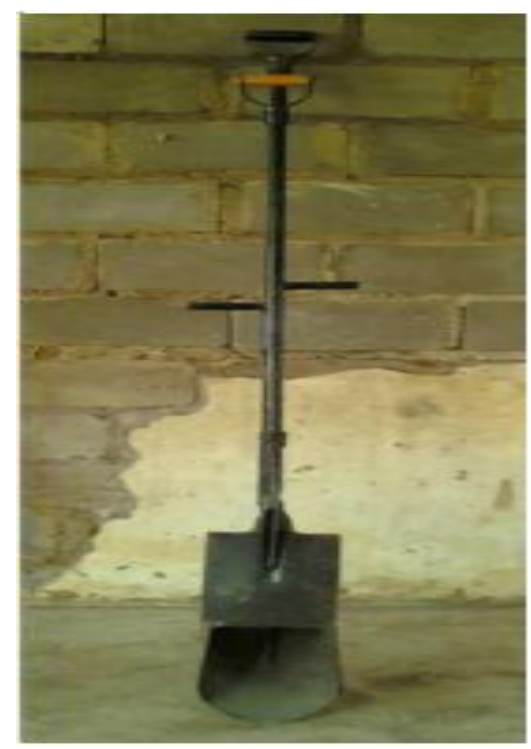

\section{Plate 2: Hand shovel/Scoop (Still and O'Riordan, 2012b)}

Furthermore, the enforcement of the use of personal protective equipments may be difficult to monitor and supervise because the manual emptying process usually takes place during the nights for fear of the stigma and ostracism (Brandes et al., 2015; Murungi and van Dijk, 2014). Additionally, the use of hand tools for desludging may face the institutional challenge as they have not been included in sanitation guidelines as options for desludging (URT, 2009; URT, 2019b). Another institutional environment that constraints the use of manual hand tools is the unavailability of disposal sites during the night hours since the designated faecal sludge disposal points operate during day time between 07:30 a.m. to 03:30 p.m. while manual desludging is always performed during the night or outside the working hours (WaterAid, 2010). In this case, the manual tools may increase the 
risk of haphazard faecal sludge disposal in Dar es Salaam.

\section{The Sludge digger}

A sludge digger is a bucket-based technology with the ability to desludge both wet and dry faecal sludge as well as shallow and deep toilets. As described by SuSaNa (2017) a sludge digger, comprises of an 8 litre bucket tied to a metal bracket, with a pivot to allow the bucket to rotate between upright and upside-down positions. A rope (normally nylon) is attached to the rim of the bucket, which is held in the operator's hand to manoeuvre as needed. The bucket fits a $25 \mathrm{~cm}$ hole. It has a telescopic handle that allows adjustment to reach deeper toilet pits, plate 5. One advantage of the sludge digger is its ability to remove faecal sludge without the removal of solid waste separately. The technique requires that the access hole is provided to the toilet pit to pass the bucket.

The application of the sludge digger in Dar es Salaam may have a mixed experience. The solution may work well with septic tanks and offset pits which have an access point for desludging. For toilets that lack access holes and have a squatting hole of less than $25 \mathrm{~cm}$, the technology may not be successful. The average pit hole size of the majority of pits in Dar es Salaam ranges between $20-30 \mathrm{~cm}$ (Brandes et al., 2015). Hence, toilets with a diameter less than 25 $\mathrm{cm}$ will miss the service or may need the slab to be broken to open. The technique may face institutional challenges in the beginning since it is yet to be included in national guidelines or promotional programmes.

\section{The excrevator}

Excrevator (Plate 4), is a modified version of a screw auger. As described by GOAL (2016), an excrevator comprises of a 4inch diameter pipe containing an auger which is rotated by a hydraulic motor that lift sludge up the pipe and out through a wye connection under which the collection container collects faecal sludge. An excrevator can desludge a $1 \mathrm{~m}^{3}$ pit in 30 min and is adopted for desludging both wetter and dry faecal sludge. A reversible operational property of the auger can easily limit blockage due to rubbish.

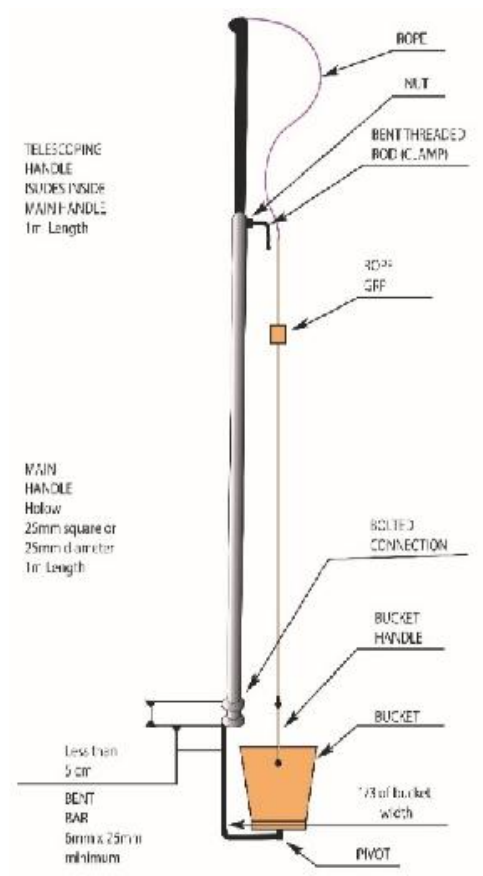

Plate 3: A fully functional sludge digger (Source: SuSaNa, 2017)

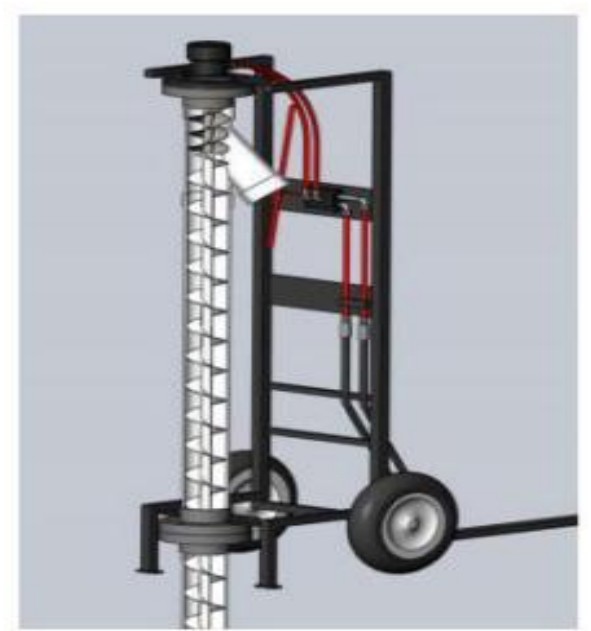

Plate 4: Excrevator (GOAL, 2016) 
The excrevator's ability to empty both wetter and dry faecal sludge while isolating solid materials in the pit during desludging process increases its potential of being used in Dar es Salaam. The presence of solid waste in a pit is a big problem in Dar es Salaam (Brandes et al., 2015). The $40 \%$ of toilets that are full in Dar es Salaam unplanned settlements provide potential customers of the service (Jenkins et al., 2015). However, as the technology is imported, a ready supply of spare parts need to be assured (Thye et al., 2011). Moreover, being manually operated equipment, it is prone to some limitations related to manual operated equipment as discussed in preceding sections such as stigma to the operators and challenges related to the operation of discharge points during night hours.

\section{The Gulper II or Rammer}

Gulper II or Rammer is a direct lift pump with an outer casing sliding up and down forcing sludge up the pump without using suction, (Plate 5). As described by GOAL (2016), the technology can reach a depth of $3 \mathrm{~m}$ unlike the former Gulper, which reached a maximum depth of $2.4 \mathrm{~m}$. The handle of Gulper II is improved to address the challenges related to ergonomics by introducing a donkey handle level arm. Rammer has a flexible outer hose outlet to facilitate hygienic operation by limiting splashes and spills. The laboratory results of performance tests revealed that Gulper II can pump sludge with a high shear strength of up to $500 \mathrm{kPa}$ compared to the Gulper I, which had a maximum capacity of $100 \mathrm{kPa}$ (Keller et al., 2017; GOAL, 2016). Gulper II can be manufactured locally; hence it is relatively easier to remain functional for a long time without down time.

Rammer's potential applicability in Dar es Salaam lies on its ability to reach a depth of up to $3 \mathrm{~m}$. In Dar es Salaam, the majority of the sanitation facilities have an average depth of around $3 \mathrm{~m}$, which can be reached by Rammer (Brandes et al., 2015). Institutional arrangement favours use of Rammer as it is in the menu of recommended desludging technological options (MoHCDGEC, 2012).

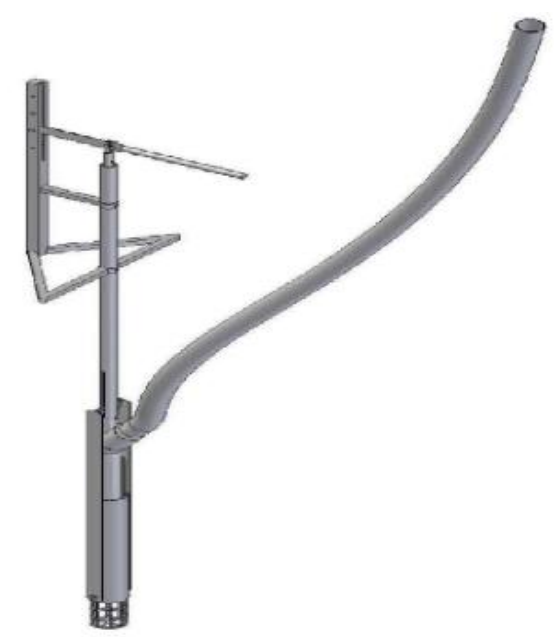

Plate 5: Gulper II or Rammer (GOAL, 2016)

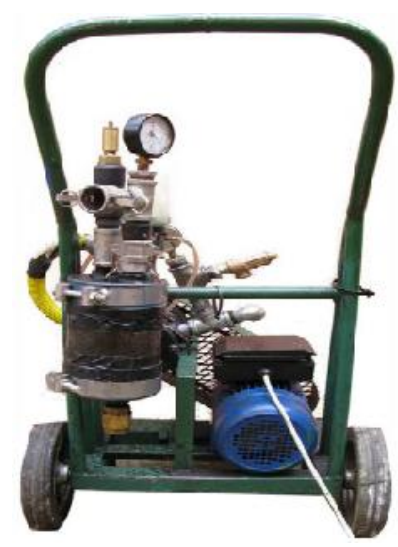

Plate 6: The eVac (Still and O'Riordan, 2012b)

\section{The eVac}

The eVac uses an electric-powered pump to suck faecal sludge. The unit comprises the vane pump, motor and a generator (Plate 6). The pump can fill a $40 \mathrm{~L}$ container in 10 seconds only, thus emptying an entire pit in 30 minutes only (Still and O'Riordan, 2012a). The technology is compact and can manoeuvre 
in narrow lanes. The eVac weighs around $63 \mathrm{~kg}$ hence can be easily carried to the vehicle and moved from one community to another. This technology solution works better with thin faecal sludge common in septic tanks and pour-flush toilets. However, the technology can be easily blocked by plastic bags and spillage may occur during desludging, which could contaminate the surroundings (Still and O'Riordan, 2012a). The eVac is a relatively sophisticated technology with some spare parts required to be ordered from the manufacturer (Thye et al., 2011).

The eVac has the potential of being applied in Dar es Salaam as some households use flush toilets and septic tanks and the number of users of pour flush is on the increase. In 2012, the coverage of pour flush toilets for the entire Dar es Salaam was $29.2 \%$ (URT, 2015), but in 2016, the use of pour flush increased to over $50 \%$ in some unplanned settlements in Dar es Salaam such as Keko Machungwa (Kasala et al., 2016). Blockage due to plastic bags in faecal sludge may not be a problem following ban of the use of plastic bags in Tanzania from June 2019 (WWF, 2019). Table 1 provides a summary of the general advantages and limitations of each of the desludging technology discussed.

\section{Modified Technology Options for Transportation of Faecal Sludge}

\section{Small pick-up trucks and motorized tricycle}

Small pick-up trucks and motorized tricycles transport sludge in drums on the load bed. The faecal sludge can be carried in sealed containers or in a single large tank mounted on the load bed of the vessel. According to Strande et al. (2014), the tricycle can carry a load of up to 1,000 litres at one time while the pick-up trucks can transport between 2,000 and 5,000 litres of faecal sludge. Major advantages of these small to medium scale transportation equipment is their ability to carry relatively larger volumes and over greater distances at higher speeds than manual transport. Spare parts for these small and medium size means of transport are usually available locally. Another advantage of this mode of transport is that they are multipurpose and can be used to transport more than one type of waste in different forms as many small containers or as a single large container. Although being multipurpose has some disadvantages of unintended misuse. For example, in Dar es Salaam, some operators changed the use of motorized tricycle from carrying faecal sludge to carrying solid waste (Godfrey and Mtitu, 2015).

\section{Transfer stations}

Faecal sludge transfer stations (FSTS) also called Septage Transfer Stations forms intermediate facilities for holding faecal sludge from onsite sanitation systems (Tilley et al., 2014; Mukheibir, 2015). In the Philippines, transfer stations are usually recommended when more than $5 \%$ of houses are inaccessible by vacuum trucks (Oxfam, 2016). As described by Strande et al. (2014), FSTS splits transportation system into primary and secondary transportation. Primary transportation involves transportation of faecal sludge from desludging points to the transfer stations and secondary transportation involves transportation of faecal sludge from the transfer stations to the final discharge points. Transfer stations can be temporary or permanently stationed and can be categorised into fixed or mobile modes. Mobile mode take the form of a tanker or trailer pulled by a tractor or tanker fitted on a wheeled chassis, but fixed mode of transfer stations include permanent storage container, modular transfer station and multi-functional permanent (Strande et al., 2014). 
Table 1: Summary of advantages and disadvantages of desludging technological options reviewed

\begin{tabular}{|c|c|c|c|}
\hline $\begin{array}{l}\text { Technology } \\
\text { option }\end{array}$ & Advantages & Disadvantages & Reference \\
\hline $\begin{array}{l}\text { Modified } \\
\text { hand tools }\end{array}$ & $\begin{array}{ll}\text { - } & \text { Manufactured locally } \\
\text { - } & \text { Can access most locations } \\
\text { - } & \text { Affordable and easy to use } \\
\text { - } & \text { Can achieve desludging of } \\
\text { entire toilet pit } \\
\text { - } \\
\text { Relies on local labour which } \\
\text { means spending funding in the } \\
\text { community } \\
\text { Process less affected by } \\
\text { breakdowns }\end{array}$ & 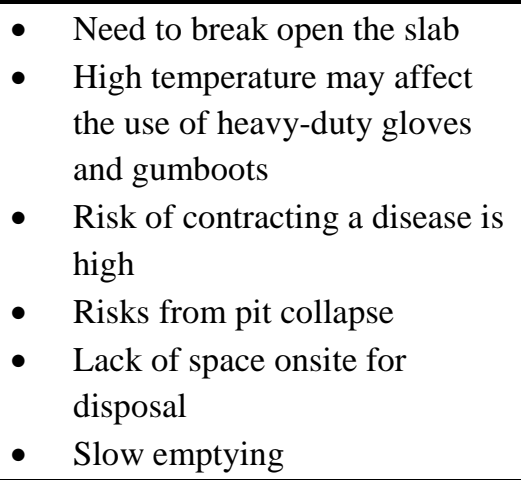 & $\begin{array}{l}\text { (GOAL, 2016) } \\
\text { (Still and } \\
\text { O'Riordan, } \\
\text { 2012b) } \\
\text { (Thye et al., } \\
\text { 2011) }\end{array}$ \\
\hline The eVac & $\begin{array}{l}\text { - Successful at desludging wetter } \\
\text { FS from flush and pour flush } \\
\text { latrines, }\end{array}$ & $\begin{array}{l}\text { - Unsuccessful at emptying drier } \\
\text { pit latrines }\end{array}$ & $\begin{array}{l}\text { (GOAL, 2016) } \\
\text { (Still and } \\
\text { O'Riordan, } \\
\text { 2012b) }\end{array}$ \\
\hline Sludge Digger & 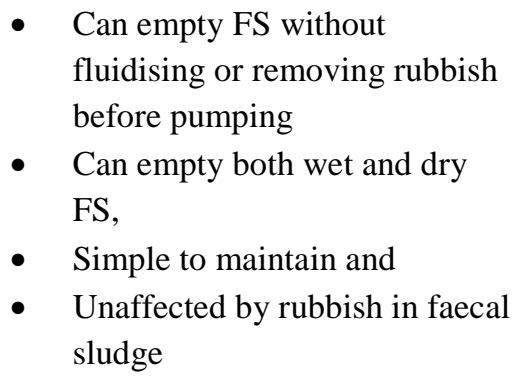 & $\begin{array}{l}\text { A need to dismantle slab for } \\
\text { the bucket to access FS in the } \\
\text { pit }\end{array}$ & (GOAL, 2016) \\
\hline Gulper II & $\begin{array}{l}\text { - } \quad \text { Can be made locally } \\
\text { - } \quad \text { Can reach toilet pits } 3 \mathrm{~m} \text { deep } \\
\text { - } \quad \text { Can access most locations } \\
\text { because of light weight } \\
\text { - } \quad \text { Flexible hose pipe facilitates } \\
\text { hygienic operation. } \\
\text { - A donkey handle allows easier } \\
\text { pumping. }\end{array}$ & $\begin{array}{l}\text { Cannot desludge pit deeper } \\
\text { than } 3 \mathrm{~m} \\
\text { Desludged faecal sludge may } \\
\text { need to be contained and } \\
\text { transported using buckets } \\
\text { - Slow emptying process }\end{array}$ & $\begin{array}{l}\text { (GOAL, 2016) } \\
\text { (Still and } \\
\text { O'Riordan, } \\
\text { 2012b) } \\
\text { (Thye et al., } \\
\text { 2011) }\end{array}$ \\
\hline Excrevator & $\begin{array}{l}\text { Compact and can easily be } \\
\text { carried } \\
\text { The auger is mounted on a } \\
\text { dolly frame to allow easy } \\
\text { movement in and out of the } \\
\text { pits. } \\
\text { The rotation of the auger can } \\
\text { be reversed which is very } \\
\text { useful for when rubbish or FS } \\
\text { gets blocked inside the pipe. }\end{array}$ & $\begin{array}{l}\text { Sophisticated and some spares will } \\
\text { need to be imported } \\
\text { Assortment of tools are needed to } \\
\text { cater for the highly variable nature } \\
\text { of FS }\end{array}$ & (GOAL, 2016) \\
\hline
\end{tabular}


In Dar es Salaam, the two sites designated for faecal sludge management are very far from the many unplanned urban settlements (Brandes et al., 2015). Gulper groups hauling faecal sludge using tricycles already find it uneconomic transporting faecal sludge for a distance of over $30 \mathrm{~km}$ to the discharge points (WaterAid, 2010; Godfrey and Mtitu, 2015). Transfer stations were introduced in Dar es Salaam in 1990s along with MAPET desludging technology. However, they were impractical because of lack of space, rejection and low institutional support (Boot, 2008). The feasibility of mobile and multifunctional transfer stations ought to be investigated in Dar es Salaam to complement the Gulpe operations.

\section{Knowledge Gaps Identified}

The review has identified three major knowledge gaps on the application of modified technological options applicable for containing, desludging, and transportation of faecal sludge in unplanned urban settlements:

- The link between technology development and field trials is weak. Innovators of technology would wish to test their technology in the field, but the process is always not straight forward (SuSaNa, 2017). Research on how efficiently to strengthen the link between technology advancement and uptake ought to be done to accelerate use of more efficient tools.

- The performance of desludging equipment is affected by the presence of solid waste in toilets as well as dense faecal sludge. However, the threshold of solid waste constituent and viscosity above which the technology cannot perform optimally need thorough investigation particularly for modified technology such as eVac and Sludge digger.

- The impact of solid waste on desludging instruments has been well documented. Nevertheless, the relationship between household characteristics and expected properties of faecal sludge in situ has not been established. Understanding of faecal sludge characteristics before desludging may assist in the determination of type of technology to be employed.

\section{CONCLUSIONS AND RECOMMENDATIONS}

The potential and constraints of modified technological options for containment, desludging and transportation in Dar es Salam context has been reviewed. The review found that Dar es Salaam context favour application of the technology though with some challenges. Availability of potential users including those with toilet filled up with faecal sludge, existence of manual pit emptying practices, households located in high water table and high infiltration, the increasing number of waterbased toilets particularly pour flush and the high coverage of lined pits makes the modified technological options technically viable. Other modified technological options have been included in the Sanitation guidelines, which indicates their institutional compatibility. Nevertheless, other local situations in Dar es Salaam constraints the use of modified technological options. Discharge points operate during the day only, a practice that may affect operation of manual desludging technology which are preferably operated during the night.

High temperature and humidity may affect use of personal protective equipment among pit emptiers. Majority of technological options have not been included in the National guidelines, a situation that may affect their promotion and roll out. The success on the use of modified technology for containment, desludging and transportation in Dar es Salaam is likely to be realized when enabling environment for their operation is improved. Improvement may include the modified technological 
option in the list of recommended technological options. The including will build confidence among users on their use and eventually improve faecal sludge management in unplanned urban settlements in Dar es Salaam.

\section{ACKNOWLEDGEMENTS}

This work is part of the Sida funded SUSTAIN project implemented jointly between the Department of Water Resources Engineering at the College of Engineering and Technology of the University of Dar es Salaam, Tanzania and the Lund University Centre for Sustainability Studies -LUCSUS, Sweden. The authors express sincere gratitude to SIDA for financial support and are highly indebted to the administration and staff of the University of Dar es Salaam and LUCSUS for their technical support.

\section{REFERENCES}

Boot N.L.D. (2008). The use of transfer stations for faecal sludge management in Accra, Ghana. Waterlines, 27(1): 71-81. https://doi.org/10.3362/17563488.2008.007

Brandes K., Schoebitz L., Kimwaga R., and Strande L. (2015). SFD Promotion Initiative Dar es Salaam, Tanzania.

Chaggu E.J. (2004). Sustainable Environmental Protection Using Modified Pit-Latrines. PhD. Thesis, Wageningen University, The Netherlands.

Chipeta W.C., Holm R.H., Kamanula J.F., Mtonga W.E. and de los Reyes F.L. (2017). Designing local solutions for emptying pit latrines in low-income urban settlements (Malawi). Physics and Chemistry of the Earth, Parts A/B/C, 100: 336-342.

https://doi.org/10.1016/j.pce.2017.02.012

EOOS and WEDC (2014). A Collection of Contemporary Toilet Designs. 48. Retrieved from http://wedc.lboro.ac.uk/knowledge/
GOAL (2016). Review of Manual Pit Emptying Equipment Currently in Use and Available in Freetown and Globally. Freetown, Sierra Leone.

Godfrey A. and Mtitu F. (2015). Pit emptying business model: Lessons from Dar es Salaam, Tanzania. $38^{\text {th }}$ WEDC International Conference, Loughborough University, UK (27-31 July, 2015).

Hawkins P., Blackett I. and Heymans C. (2013). Urban Sanitation: An Overview. (August).

Jenkins M.W., Cumming O., Scott B. and Cairncross S. (2014). Beyond 'improved' towards 'safe and sustainable' urban sanitation: assessing the design, management and functionality of sanitation in poor communities of Dar es Salaam, Tanzania. Journal of Water, Sanitation and Hygiene for Development, 4(1):

131. https://doi.org/10.2166/washdev.2013.18 0

Jenkins M.W., Cumming O. and Cairncross S. (2015). Pit latrine emptying behavior and demand for sanitation services in Dar Es Salaam, Tanzania. International Journal of Environmental Research and Public Health, 12(3): 2588-2611. https://doi.org/10.3390/ijerph120302588

Kasala S.E., Burra M.M. and Mwankenja T.S. (2016). Access to improved sanitation in informal settlements: The case of Dar es Salaam. Current Urban Studies, 4: 23-35. https://doi.org/10.4236/cus.2016.41003

Katukiza A.Y., Ronteltap M., Niwagaba C. B., Foppen J.W.A., Kansiime F. and Lens P.N.L. (2012). Sustainable sanitation technology options for urban slums. Biotechnology Advances, 30(5): 964 978.

https://doi.org/10.1016/j.biotechadv.2012 .02 .007

Keller M., Chingoma L. and Fawz A. (2017). Manual Pit Emptiers Freetown, Sierra Leone. GOAL, 4th International Faecal Sludge Management Conference. Retrieved from https://www.susana.org/_resources/docu 
ments/default/3-2742-7-1488815391. et alpdf

Manus C. (2011). What you need to know about emptying pits and tanks with vacuum tankers, large and small FSM Seminar 14-15 March 2011, Durban, South Africa, 16-17.

Mara D. (1985). The Design of Pour-Flush Latrines: TAG Technical Note No. 15. The World Bank, Washington, DC, USA. Mara D., Drangert J.O., Nguyen V.A., Tonderski A., Gulyas H. and Tonderski K. (2007). Selection of sustainable sanitation arrangements. Water Policy, 9(3): 305-318. https://doi.org/10.2166/wp.2007.009

Mayo A.W. and Mubarak T. (2015). Challenges of adoption of urine-diversion dry toilets technology as sanitation option by coastal communities of Mkuranga District in Tanzania. African Journal of Environmental Science and Technology, 9(5): 482-492. https://doi.org/10.5897/AJEST2014.1779

MoHCDGEC. (2012). National Sanitation Options and Construction manual. Dar es Salaam, Tanzania.

Morgan P. (2013). Methods of emptying Blair VIP toilets: Further trials with the tank version. Aquamor-Harare, Zimbabwe.

Mukheibir P. (2015). A guide to septage transfer stations. SNV, Netherland's Development Organisation by Institute for Sustainable Futures, University of Technology Sydney. Broadway, Australia.

Murungi C. and van Dijk M.P. (2014). Emptying, Transportation and Disposal of feacal sludge in informal settlements of Kampala Uganda: The economics of sanitation. Habitat International, 4: 6975 .

https://doi.org/10.1016/j.habitatint.2013.1 0.011

National Bureau of Statistics (NBS) Tanzania (2015). Tanzania Integrated Labour Force Survey: Analytical Report 2014, National Bureau of Statistics; The World Bank; UNICEF; DFID;
International Labour Organization (ILO); Foreign Affairs, Trade and Development, Canada, United Republic of Tanzania, Dar es Salaam.

O'Riordan M. (2009). Investigation into Methods of Pit Latrine Emptying. Partner in Development, Ipswich, Massachusetts, USA.

Oxfam (2016). Septage Management: Leader's Guidebook-Philippines Edition. Manila, Philippines.

Russel K.C., Hughes K., Roach M., Auerbach D., Foote A., Kramer S. and Briceño R. (2019). Taking ContainerBased Sanitation to Scale: Opportunities and Challenges. Frontiers in Environmental Science, 7: 1-7. https://doi.org/10.3389/fenvs.2019.00190

Safari J., Mohamed H., Dimoso P., Akyoo W., Odhiambo F., Mpete R., Massa K. and Mwakitalima A. (2019). Lessons learned from the national sanitation campaign in Njombe district, Tanzania. Journal of Water, Sanitation and Hygiene for Development, 9(4): 754-764. https://doi.org/10.2166/washdev.2019.27 4

Semiyaga S., Okure M.A.E., Niwagaba C. B., Katukiza A.Y. and Kansiime F. (2015). Decentralized options for faecal sludge management in urban slum areas of Sub-Saharan Africa: A review of technologies, practices and end-uses. Resources, Conservation and Recycling, 104:

109-119. https://doi.org/10.1016/j.resconrec.2015. 09.001

Still D. and O'Riordan M. (2012a). Tackling the Challenges of Full Pit Latrines. Volume 2: How fast do pit toilets fill up? A scientific understanding of sludge build up and accumulation in pit latrines (Vol. 3). https://doi.org/978-1-43120293-5

Still D. and O'Riordan M. (2012b). Tackling the Challenges of Full Pit Latrines. Volume 3: The development of pit emptying technologies (Vol. 3). https://doi.org/978-1-4312-0293-5 
Strande L., Ronteltap M. and Brdjanovic D. (2014). Faecal sludge management: Systems approach for implementation and operation. IWA Publishing, London, UK.

Sustainable Sanitation Alliance (SuSanA): Vision Document. (2008). Towards more sustainable sanitation solutions. Retrieved from https://www.susana.org/en/knowledgehub/resources-andpublications/library/details/267

Sustainable Sanitation Alliance (SuSanA) (2017). Further Development of Sludge Digger and Dipper. Retrieved from https://forum.susana.org/99-faecalsludge-transport-including-emptying-ofpits-and-septic-tanks/21952-furtherdevelopment-of-sludge-digger-anddipper

Sustainable Sanitation Alliance (SuSanA) (2019). The Shit Flow Diagram (SFD). Retrieved from https://sfd.susana.org/

Thye Y.P., Templeton M.R. and Ali M. (2011). A Critical Review of Technologies for Pit Latrine Emptying in Developing Countries. Critical Reviews in Environmental Science and Technology, 41(20): 1793-1819. https://doi.org/10.1080/10643389.2010.4 81593

Tilley E., Lüthi C., Morel A., Zurbrügg C. and Schertenleib R. (2014). Compendium of Sanitation Systems and Technologies. Development, 180. https://doi.org/SAN12

Tilmans S., Russel K., Sklar R., Page L., Kramer S. and Davis J. (2015). Container-based sanitation: assessing costs and effectiveness of excreta management in Cap Haitien, Haiti. 27(5): 89-104. https://doi.org/10.1177/09562478155727 46

UNICEF and WHO (2019). Progress on household drinking water, sanitation and hygiene 2000-2017: Special focus on inequalities. In Launch version July 12 Main report Progress on Drinking Water, Sanitation and Hygiene. Retrieved from https://washdata.org/reports

United Republic of Tanzania (URT) (2009). The Water and Sanitation Act, 2009. Retrieved from http://extwprlegs1.fao.org/docs/pdf/tan14 2669.pdf

United Republic of Tanzania (URT) (2015). Housing Condition, Household Amenities and Assets Monograph. Gazette, IV(0), 1-24.

United Republic of Tanzania (URT) (2016). Tanzania National Guideline for Verification and Certification of ODF Communities.

United Republic of Tanzania (URT) (2019a). Tanzania in Figures in 2018. National Bureau of Statistics Dodoma, Tanzania.

United Republic of Tanzania (URT) (2019b). The Water Supply and Sanitation Act, 2019. Retrieved from http://www.parliament.go.tz/acts-list

WaterAid (2010). Pit emptying Business in Temeke-DSM. Retrieved from https://sswm.info/sites/default/files/refe rence_attachments/WATERAID 2010 Pit Emptying Business.pdf

World Bank Group (WBG) (2019). Evaluating the Potential of ContainerBased Sanitation. 1818 H Str.

World Health Organization (2018). Guidelines on sanitation and health. Geneva, Switzerland.

WWF (2019). Tanzania bans the use of plastic bags. Retrieved May 8, 2019, from

https://wwf.panda.org/wwf_offices/tan zania/?345830/Tanzania-bans-the-useof-plastic-bags 